\title{
Las borracheras secretas de los abuelos de Panchimalco
}

\author{
The secret drunkenness of Panchimalco's grandpas
}

\author{
Carlos Felipe Osegueda-Osegueda' \\ Miguel Ángel Hernández ${ }^{2}$ \\ Miguel Ángel Rodas-Ramírez ${ }^{3}$ \\ Josué Misael Dionicio-Nerio ${ }^{4}$ \\ David Ernesto Pérez-Domínguez ${ }^{5}$ \\ Universidad Tecnológica de El Salvador \\ carlos.osegueda@utec.edu.sv
}

Recibido: 21/07/17- Aceptado: 19/10/17

\section{Resumen}

El presente artículo, es el extracto de una investigación que demuestra cómo una práctica cambia con el devenir de los años y se modela según los contextos económico, social y político. Con las herramientas que facilita la etnografía como método de la antropología, se estudió la producción de chicha en el casco urbano de Panchimalco y su relación con las festividades religioso-populares. Una parte de los hallazgos de campo gravita entre la categorización de etapas de producción subyugadas por los sistemas fiscales que establecieron los gobernantes de turno, el golpe que ha implicado el desmantelamiento del Estado en la posguerra y la etapa actual, que se centra en la presentación de lo indígena como elemento exótico que incentiva el turismo.

\section{Palabras clave}

Etnología - El Salvador; Actividades culturales- El Salvador; Folclor - El Salvador; Turismo - El Salvador

\section{Abstract}

This article is the excerpt of a research investigation which demonstrates how some practices change as time goes by and how they are shaped around the social, political and economic contexts. Taking advantage of ethnography as an anthropological method, the production of chicha (Salvadorean moonshine) downtown Panchimalco and its relation with the popular-religious celebrations was taken as the subject of study. Part of the findings from the field study lays in the categorization of the production stages subjugated by the tax systems established by each governor; its consequences include the strike that represented their dismantling in the hands of the Estate during the postwar and the present time, which has centered in presenting indigenous elements as an exotic component that draws tourism to the country.

\section{Keywords}

Ethnology - El Salvador; Cultural activities - El Salvador; Folklore - El Salvador; Tourism - El Salvador

1 Profesor titular de la asignatura de Antropología Social, Utec.

2 Instructor de la asignatura de Antropología Social, Utec.

3 Estudiante investigador de la asignatura de Antropología Social.

4 Estudiante investigador de la asignatura de Antropología Social.

5 Estudiante investigador de la asignatura de Antropología Social. 
A continuación se presentan unos conceptos claves para la mejor comprensión del presente artículo.

\section{Difusionismo}

Según Barfield (1997), difusionismo "es la transmisión de elementos de una cultura a otra. Esos elementos son transmitidos por agentes que utilizan medios identificables y están sujetos a diversas barreras o efectos de filtro".

\section{Particularismo histórico}

Según Pérez (1999), el particularismo histórico es un enfoque que considera que cada cultura tiene su larga y única historia (unicidad histórica) y, por lo tanto, se niega la posibilidad de la perspectiva de una ciencia de la cultura generalizadora. (...) No existe una cultura general o global, cada cultura sigue un camino único y particular y para entenderla hay que estudiarla por separado.

\section{Sincretismo}

Para Hope y Mora (2000), sincretismo es aquella situación en la que los aspectos nuevos de una cultura se funden con los antiguos, sin que estos desaparezcan. Suele darse en situaciones de dominación, en contextos en los que los elementos de la cultura dominada se mezclan con los de la dominante, generando rasgos y elementos nuevos, híbridos, aunque hay quienes consideran que no hay una aceptación total de estos elementos, sino que una reinterpretación que permite su asimilación en un contexto diferente que en el que fueron generados.

\section{Cultura}

Para Tyler (1891), cultura es ese complejo conjunto que incluye el conocimiento, las creencias, las artes, la moral, las leyes, las costumbres y cualesquiera otras aptitudes y hábitos adquiridos por el hombre como miembro de la sociedad.

\section{Mito}

Según Solsana (s.f.), el mito al parecer es una explicación posterior a un rito. Pero también es cierto que todo ritual remite al mito como explicación, pues es en el donde se narran las acciones arquetípicas que imitamos, o de las que participamos, en el ritual; $y$ dan sentido a nuestra existencia en el entendido de ser respuesta última, fundamento.
Rito

Según Gómez (2002), el rito es "algo actuado en clave simbólica, es práctica, acción, secuencia de actos cargados de simbolismo culturalmente codificado (...) constituye, ante todo, una práctica, un mecanismo simbólico de la vida social, que, a escala general o sectorial, contribuye a la regeneración permanente o periódica de esa vida, a lo largo de las generaciones, mediante su repetición".

La investigación "Sincretismo y religiosidad popular: la bebida embriagante en el mito y rito ancestral en Panchimalco" inició con el enfoque etnográfico y desde el método cualitativo de recolección de información.

Las técnicas de las que puede valerse la etnografía son: observación directa, conversación, método genealógico, trabajo con informantes clave, historias de vida de personas particulares, descubrimiento de creencias y percepciones de los miembros de la comunidad, orientar el trabajo a diversos problemas, investigación en equipo e investigación longitudinal (Kottak, 2006: 55).

Este trabajo inició con seis visitas de campo al casco urbano de Panchimalco para crear el rapport, es decir, el establecimiento de relaciones con los miembros de la comunidad para evitar ser visto como un extraño, un intruso. ¿Qué se hizo para romper la barrera de la desconfianza? Se realizaron seis visitas. Los investigadores caminaron en el casco urbano, permanecieron en la iglesia, saludaron, visitaron el parque, platicaron amenamente con los vendedores ambulantes, con los comerciantes que regentan puestos en el mercado y con los que están frente a la iglesia, con miembros de Alcohólicos Anónimos que suelen reunirse en la Casa de la Cultura de la localidad a platicar de la vida confinada en la abstinencia.

De estas visitas, se obtuvo información básica sobre inseguridad, variaciones climáticas, enfermedades, la dependencia del turismo en la vida de los comerciantes, las redes de los comerciantes de bebidas embriagantes, entre otros.

Se hizo para habituarse a la mirada de los lugareños y evitar ser vistos con recelo. En todo esto, ha servido acercarse sin prejuicios a los vecinos de manera respetuosa. 
El siguiente paso fue establecer contacto con los miembros de la Casa de la Cultura que están relacionados con los productores de bebidas embriagantes de la localidad; y ellos mismos también son productores.

En este proceso se ocuparon las siguientes técnicas:

Entrevista semiestructurada: se aplicó con la finalidad de obtener información pertinente, oportuna y acertada para los intereses del proceso de conocer, describir, descubrir e interpretar los antecedentes, construcción mitológica y ritualidad en torno a la elaboración de bebidas fermentadas en un contexto de religiosidad popular. Esta técnica se desarrolló mediante un cuestionario flexible, puesto que dio a los entrevistados la oportunidad de ampliar su opinión y proporcionar información adicional que enriqueciera la investigación.

Efecto bola de nieve: una vez identificados los informantes claves, se procedió a localizar por medio de estos a otros sujetos que estuvieran inmersos en el fenómeno de estudio, es decir, productores locales de la bebida tradicional chicha, logrando identificar a dos, sin embargo, estos se mostraron esquivos e indispuestos a participar con el equipo investigador. Toda la información se archivó.

Los resultados de la investigación fueron interpretados a partir de los contextos de consumo de bebidas embriagantes, la religiosidad popular, el sincretismo, la información histórica obtenida con la revisión bibliográfica, entre otros. Posteriormente se socializaron los resultados.

\section{Los hallazgos en el campo}

1. Categorización de las etapas del consumo de chicha de acuerdo con el análisis de información por parte del equipo de investigación

\section{Precolombina}

Los contextos tradicionales del consumo de la chicha -que es una variante más de bebida fermentadatambién han cambiado. Ya se ha explicado que los pueblos mesoamericanos la consumían con propósitos mágicoreligiosos, ceremoniales y para celebrar la fertilidad de la tierra. Hubo, además, una restricción político-ideológica: solo la podían beber las élites porque, como bebida espiritual, les servía para alcanzar a los dioses; detrás de esto puede identificarse uno de los pilares del modo de dominación ideológico de la época: solo los miembros de la élite tenían la capacidad de acercarse a los dioses, mientras el resto de la población debía servirles porque solo los poderosos podían interceder ante los dioses.

¿Qué hay de fondo? Era el producto que solo las élites podían consumir de forma exclusiva. Hay un elemento generalizador: estratificación social. Religión, mito, poder, dominación, todos se funden en una bebida: la chicha.

\section{Colonia}

La segunda etapa del consumo ocurre con la invasión española: es la etapa de la colonización, de la que pueden subdividirse dos momentos: el consumo ritual vinculado con las celebraciones que se realizaban antes de la llegada de Ios invasores; y el consumo para sustraerse de la realidad.

¿Embriaguez como medio de sustracción de la realidad? Henríquez, Sevilla y Torres (2013) lo explican así: "Los invasores esclavizaron, humillaron y asesinaron a millones de indígenas y provocaron en los sometidos un 'desgano vital'. Por ejemplo en el actual México la población nativa disminuyó de 25 millones a 1 millón, entre 1519 y 1532; en Honduras fue reducida de 800.000 a 32.000 , y en las Antillas fue exterminada". A eso los autores sumaron el tráfico de esclavos indígenas, las guerras y otros enfrentamientos entre los que resistieron y los invasores. Es cierto que en ese período hubo leyes que los protegieron -las Leyes de Indias es un ejemplo-, pero en la práctica quedaron nada más en eso: en papeles.

Esta situación de esclavitud, mortalidad y exterminio sufrida por los indígenas generó una especie de 'desgano vital' como dicen los autores arriba citados- y desencadenó en algunos de ellos una serie de prácticas y actitudes conducentes a la evasión e indiferencia hacia la realidad, casi siempre a través del consumo de alcohol. Esta actitud fue fuertemente cuestionada y criticada por los españoles, quienes acusaron constantemente en las crónicas a los indígenas de "ser 'perezosos', 'indolentes' y 'apáticos'". Es posible que consumieran chicha como mecanismo para evadir la dura realidad y explotación a la que estaban siendo sometidos (ibídem: 52). 


\section{República}

En la etapa republicana, el Estado mantuvo el control sobre la producción de las bebidas alcohólicas.

Claudia Vega, de 71 años de edad, escuchó hablar acerca de la chicha por primera vez hace 67 años. David, su abuelo, cargaba todos los días un pequeño cántaro con "agua dulce" que se llevaba a su trabajo en el campo. Afanado trabajaba desde las cinco de la mañana hasta el mediodía. Con el sol en el cenit se tomaba un descanso, abría el depósito y tomaba hasta saciarse. Luego continuaba. "¿Por qué toma eso, abuelo?", le preguntaba Claudia de cuatro años. "Para el calor, hija", le respondía.

Entre 1930 y 1970 la producción y el consumo eran normales, pero clandestinas. En las zonas rurales las familias, según la informante, solían mantener un cántaro con la bebida "fuertecita"; la consumían los hombres, principalmente, cuando estaban en el trabajo. Esto inclina a creer que labraban la tierra en un relativo estado de ebriedad; y recuerda los tiempos de la Colonia. Aparte hay una especie de justificación de la embriaguez que se mezcla con elementos quizá picarescos y otros asociados con la medicina. Vega dijo creer que su abuelo gozó de una salud de hierro porque todos los días 'empinaba el codo' (bebía chicha).

Oliva Mancía (2011) explica que entre 1800 y 1900 primaron en la narrativa oficial los discursos para erradicar el alcoholismo; pero en la práctica era el Estado el que ganaba millonarias rentas por tener el monopolio de la producción de bebidas alcohólicas. En 1907, por ejemplo, patentados abrieron 91 estancos de aguardiente; al año siguiente el número de estancos aumentó a 158. La producción de botellas con alcohol aumentó de 3.522, en 1900, a 241.618, en 1913. De 1886 a 1913 fueron consumidas, según los registros de Hacienda de la época, 57.417.759 botellas de aguardiente.

Había dos leyes fundamentales que regulaban la producción de bebidas embriagantes: el Reglamento de Licores y la Ley de Administración de Rentas. La primera reconoce tres tipos de fábricas: de alcoholes, de aguardiente y de licores. También es mencionada la producción de vinos de frutas, pero para ejercerla se necesitaban permisos especiales. Cortez cita estadísticas publicadas en 1948 en La Prensa Gráfica de capturados por producir chicha: "Ocho son hombres, 17 son mujeres y fueron desmanteladas 14 fábricas".
Loucel (citado en Escalante Arce, 2008) explica que los dos principales pilares tributarios del Estado salvadoreño, desde 1898 hasta 1930, fueron los que recolectaba de las rentas del café y de licores.

\section{Turística}

En los años 90 y entrado los años 2000 la Casa de la Cultura pagaba los ingredientes y la preparación de la chicha y la regalaba a los turistas que llegaban a la celebración de Las Palmas y a las fiestas patronales que se celebraban en septiembre en honor a la Santa Cruz de Roma. Pero desde hace siete años eso ha cambiado: decidió venderla desde que sus arcas entraron en crisis y quedó endeudada.

Como ya se ha señalado, el municipio articula la promoción del turismo con las celebraciones que tienen aroma indígena, por las tradiciones -que obviamente están cargadas de sincretismo- para atraer más divisas a las arcas municipales. Es necesario repetir, además, que en el casco urbano no hay cantinas. Ella y Vega se encargan en la actualidad de mantener "la costumbre" de vender la chicha en las celebraciones religioso-populares.

Entre 2009 a 2013, de acuerdo con Guzmán, las celebraciones se inundaban de turistas, vecinos del casco urbano y de las zonas rurales que deambulaban un rato en la procesión y luego corrían a beber chicha. Pero con la intensificación de la violencia, entre los años 2014 y 2016, la afluencia cayó drásticamente. "Ese montón de bichos que están presos venían a tomar chicha. Ahora todos están guardados", - afirmó.

A principios de 2017, el departamento de Turismo de la alcaldía de Panchimalco empezó a implementar el Plan Maestro de Turismo, que está compuesto de tres pilares: desarrollo local, comercial y social. En 2009, el Frente Farabundo Martí para la Liberación Nacional (FMLN) ganó las elecciones en el municipio, y desde entonces lo administra. En los últimos ocho años, la alcaldía ha remozado el espacio público para volverlo atractivo a los visitantes. Ejemplo de ello son: el parque Escultórico, el parque Acuático, el rescate del sitio Las Cruces y el aporte en dinero que da al "Festival de las flores y las palmas".

¿Por qué se interesa en las celebraciones como el "Festival de las flores y las palmas" la alcaldía? Daniel Elías, empleado del Departamento de Turismo, explicó que el principal 
interés es mantener un estrecho vínculo con las cofradías y, mediante la incipiente promoción turística, procurar buena fama a su gestión pública y al municipio.

El empleado público detalló que Panchimalco tiene dos grandes rutas turísticas: la interna, que incluye visitas a la Casa de la Cultura, Casa Taller de Encuentros, sitio Las Cruces, parque Escultórico, iglesia, entre otros. La Casa de la Cultura del municipio se concentra en visitas a los parques de la Familia y el Balboa, el obelisco y Los Planes de Renderos, entre otros.

"Promocionamos más la ruta interna" -aclaró Elías-. ¿Qué papel juegan lo indígena y la producción y consumo de chicha? Según él, no hay nada indígena que ofrecer en el recorrido. O más bien esa fue su primera respuesta. Luego hizo una especie de rectificación: la celebración de Las Palmas, por ejemplo, mezcla elementos indígenas con catolicismo, y la chicha es la bebida oficial para estos momentos. "Es una de las bebidas que se ha estado conservando" — comentó.

Puede deducirse que en la actual etapa turística prima la producción y consumo con propósitos económicos y de diversión. Las productoras en la Casa de la Cultura mantienen la costumbre porque - debe admitirse - obtienen una ganancia en dinero.

\section{2) Turismo, migraciones, fin de la producción casera}

¿Qué cambió tanto como para que en el casco urbano de Panchimalco la costumbre de producir chicha para consumo personal se perdiera? Hay dos puntos trascendentales: la crudeza de la guerra civil y la radical modificación del Estado a finales de los años 80. Ambos contienen elementos militares, políticos, económicos, de migración e ideológicos. Para explicar esta parte es necesario antes establecer la relación entre identidad y memoria cultural.

Pierre Nora, Chaim Yerushalmi y Jan Assman (citados en Heller, 2003) señalan que la memoria cultural contiene objetivaciones que dan significados concentrados que comparte un grupo de personas. Pueden ser objetos como papeles sagrados, crónicas, poesía, monumentos, señales, símbolos, alegorías, pero sobre todo está incorporada regularmente en manifestaciones como fiestas, ceremonias, ritos, entre otros. También está asociada con lugares en los que ha ocurrido un suceso significativo o único. Por ejemplo: los judíos construyeron durante mucho tiempo una memoria en común.

La memoria no es una copia exacta del pasado, sino la reproducción de ese pasado con un sentido actual. Mijail Bajtin (citado en Hernández, 2006) dice que a través de la memoria se comparten significados y se reconstruye con otros.

Pero la memoria cultural se fractura o se rompe cuando suceden eventos límite, traumáticos, que sobrepasan el umbral de lo humanamente soportable. Es entonces cuando las prácticas u objetos que daban significado a la memoria dejan de tener importancia.

Martínez Quintero (2009) hizo un estudio etnográfico en las comunidades víctimas del desplazamiento forzado en Colombia. Algunas de sus reflexiones explican cómo cambia la vida de las personas que sufren la guerra, cómo su memoria cultural se diluye hasta el límite.

La violencia y la guerra configuran, para los sobrevivientes, una experiencia límite en la medida que traspasa el umbral de lo corporalmente soportable, en el sentido que deja de ser una dificultad domesticable para convertirse en un acontecimiento que abruptamente transforma la cotidianidad, enrarece y contamina (...) A partir de estos hechos la cotidianidad de los sujetos no es la misma, su resignificación está enmarcada inicialmente en el cambio de lugar habitado, la transformación de los referentes de ubicación y de todo el contexto en el cual se erigía una concepción de un mundo más o menos estable (ibídem).

Los informantes explicaron que antes de iniciar la guerra civil lo común era, aunque clandestinamente, que la gente en sus casas preparaba chicha para consumo personal. Siempre existió el miedo de ser descubierto y llevado a la cárcel - o por lo menos de soportar una golpiza de la guardia-; al estallar el conflicto ese miedo se intensificó. De 1979 a 1982 el Estado salvadoreño cometió los peores crímenes de guerra, de acuerdo con el informe de la Comisión de la Verdad. Odilia Guzmán lo resume así: "La gente pensaba que si los hallaban (con chicha en la casa) se los iban a llevar".

En pleno conflicto todavía vivían "unos pocos señores" - según Vega- que sabían preparar chicha. Pero también 
por miedo engavetaron las prácticas que habían aprendido de sus abuelos. Puede concluirse que en este momento ocurre el corte, el vacío: los ancianos dejaron de preparar, ya no transmitieron el conocimiento a sus hijos y la costumbre se perdió. El 16 de enero de 1992 el Estado y la insurgencia del FMLN firmaron los Acuerdos de Paz, y la pena por producir chicha pasó a ser cosa del pasado; también la costumbre de prepararla. "Según vinieron las nuevas generaciones se fue perdiendo la tradición", agregó.

Con las reformas institucionales implementadas con los Acuerdos de Paz desaparecieron los antiguos cuerpos de seguridad. La persecución a la producción y el consumo desaparecieron. Incluso, en aquellos años, la incipiente Policía Nacional Civil jamás desempeñó un papel inquisidor contra la gente que producía la chicha, pero la violencia de la guerra ya había herido de muerte la tradición.

\section{El golpe final}

Para modificar su estrategia de desarrollo los países latinoamericanos, por consejos del Banco Mundial (BM) y del Fondo Monetario Internacional (FMI), implementaron las siguientes medidas: liberalización económica, privatización de las empresas estatales, reducción de la intervención estatal en la economía en general y recorte de la inversión pública. Los grandes organismos financieros internacionales habían interpretado que las crisis económicas latinoamericanas eran consecuencia de la distorsión en la asignación de dinero en los presupuestos generales de cada país, erróneas políticas proteccionistas, la intervención estatal en la economía, ineficiencia del sector público, entre otros (Moreno et al, 2004).

En noviembre de 1989, el Instituto de Economía Internacional reunió en Washington a poderosos empresarios, economistas y representantes de países latinoamericanos para presentarles el documento titulado "Lo que Washington quiere decir por reforma de la política". En él mencionaba medidas como las siguientes:

- Eliminar todos los subsidios.

- Incrementar el ingreso fiscal al ampliar la base tributaria.

- Liberalizar las tasas de interés.

- Establecer un régimen flexible de tipo de cambio.

- Liberalizar el comercio exterior.
Este horizonte teórico, conocido como "Consenso de Washington", llegó a El Salvador a principios de los años 90 con tres tareas iniciales: la reestructuración de la burocracia estatal, la privatización de los servicios públicos y la creación de leyes para beneficiar a los empresarios nacionales y extranjeros. El BM y el FMl financiaron el Programa de Modernización del Sector Público, que contenía medidas para reformar la administración pública, la creación de un nuevo sistema financiero y de los incentivos para atraer a los inversionistas transnacionales (Moreno, 2004).

Ramos (2012) señala las siguientes características de la globalización: deslocalización laboral, flexibilización del mercado laboral, precariedad laboral, formación de capitales transnacionales, aplicación del darwinismo social en la mayoría de aspectos de la vida, debilitamiento del Estado como regulador de la relación entre el capital y el trabajo, distribución cada vez más desigual de la riqueza, crecimiento de la pobreza mundial, migración de las poblaciones de los países periféricos al primer mundo y desintegración familiar, entre otros.

En esta investigación se retoma la migración y se relaciona con el resquebrajamiento de las identidades en los municipios. "La fisonomía de los municipios, pueblos y cantones del país se ha transformado gracias a la arquitectura de las remesas" —dice la autora.

La migración y las remesas casi siempre van de la mano. En su investigación, Ramos descubrió que el dinero que mandan los migrantes salvadoreños modifica completamente los modos de vida: en los pueblos cambian los servicios básicos, la arquitectura de las viviendas y otros elementos que provocan la "transnacionalización de la sociedad salvadoreña".

La globalización y las migraciones modificaron las conductas y los intereses de los salvadoreños. Eso, a estas alturas, es una verdad evidente. ¿Y esto a qué viene al caso? La economía es un elemento más que moldea la cultura. El sistema económico implementado desde los años 90 liberalizó el comercio, es decir, propició la entrada al mercado de todo tipo de productos que quizás tuvieron mucha más funcionalidad que los productos artesanales que los salvadoreños preparaban en sus casas hace unos 40 años. En esa medida, lo que pierde pragmatismo suele desaparecer. La cultura es así: tiene sentido cuando es práctica, cuando soluciona un problema, de lo contrario, se pierde. 
Cerrando el foco de atención se llega al tema central: la desaparición de la producción casera de chicha en Panchimalco. ¿Cómo se llega hasta esta parte? Se ha señalado que en las épocas colonial y republicana el Estado prohibió su preparación y consumo porque, al no ser una bebida gravada, provocaba la pérdida de las rentas que sí estaban gravadas. Pero esa persecución —que estuvo a cargo de la Policía de Hacienda - fue insuficiente porque, en secreto, las familias preparaban la bebida para consumo personal. La situación se agravó en los años 80 con el estallido de la guerra civil y el enterramiento de las tradiciones como consecuencia del proceso traumático. Llegaron los Acuerdos de Paz y la producción ya no era ilegal. ¿Por qué a los productores ya no les interesó tener en casa sus cántaros con chicha? ¿Por qué a los nietos no les interesó aprovechar el espacio de libertad que significó el fin de la persecución de la producción de chicha en casa?

El Estado inició la implementación estructural de la globalización, la precarización obligó a migrar y los migrantes modificaron su cultura una vez en el extranjero; y esta modificación la trasladaron a sus familiares mediante las remesas.

Con dinero en mano, los salvadoreños vieron otro mundo, se interesaron por otras cosas; revivir las prácticas de sus abuelos ya no tenía sentido.

\section{Conclusiones}

El mito y el rito de producción de chicha tienen origen ancestral. Surgen en la época de la Colonia debido al sincretismo característico del momento, se conservan en la etapa republicana, mientras que en el momento turístico las artesanas de la chicha, aglutinadas en la Casa de la Cultura, conservan el rito de elaborarla para el "Festival de las flores y las palmas"; pero el mito sufre una hibridación adicional: mezcla la costumbre (festival sin chicha no es festival) y la construcción de un aparataje turístico (la chicha es un atractivo turístico complementario al festival).

No se evidencia relación entre el aprendizaje del rito y la herencia del conocimiento entre clanes o linajes. El maestro artesano no tiene necesariamente una relación familiar con el aprendiz, más bien, esta relación actualmente tiene una connotación de interés comercial.
La configuración actual (desde 1992 al presente) de la sociedad pancha presenta manifestaciones de violencia a través de estructuras delincuenciales que han modificado la ritualidad de la elaboración de la chicha en la etapa turística, pues las artesanas de la Casa de la Cultura ya no buscan raíz de güiscoyol en los cantones del municipio debido a que no perciben garantía de respeto a su integridad. En la época de la posguerra otro proceso social han modificado el ritual, las artesanas ya no entierran los cantaros de chicha, ya que no tienen necesidad de hacerlo debido a que desde 1992 no hay cuerpos de seguridad que persigan la elaboración de esta bebida.

Existen opiniones encontradas respecto al tema de la chicha, así como un punto de común acuerdo entre los discursos de la alcaldía municipal y la Casa de la Cultura: ambas instituciones otorgan reconocimiento a la chicha como elemento esencial de las costumbres propias de la comunidad, hecho que la posiciona como producto exento de tasas municipales.

Existe cooperación entre la alcaldía y la Casa de la Cultura en el desarrollo de un programa de promoción y conservación del "Festival de las flores y las palmas" y de las fiestas patronales, a pesar de esto no hay un fondo destinado explícitamente a la protección de la chicha como patrimonio cultural de Panchimalco, por ser considerada un elemento complementario a las festividades.

Existe divergencia de opinión en torno a los ingresos que genera el turismo como producto de las festividades populares, pues la Casa de la Cultura afirma que sí se produce un arribo de turistas, mientras que la alcaldía, por el contrario, manifiesta que hay afluencia de "visitantes" y no de turistas, por lo que no se generan ingresos económicos de forma directa a las arcas municipales.

\section{Referencias}

Barfield, T. (1997). Diccionario de Antropología.

Pérez, W. (1999). El estudio de casos. Sarabia Sánchez, FJ, Metodología para la Investigación en Marketing y Dirección de Empresas", Ediciones Pirámide, Madrid.

Tyler, E. (1891). Primitive culture.

Solsona, H. (s.f.). Mito y ritual. 
Gómez, P. (2002). "El ritual como forma de adoctrinamiento". Universidad de Granada: Enero 2002. Recuperado de http://www.ugr.es/ pwlac/G18_01Pedro_Gomez_ Garcia.html

Kottak P. (2011). Antropología Cultural. McGraw-Hill: Ciudad de México, México.

Henríquez, J.; Sevilla, J.; Torres, J.; Rivera, W. (2013) “Historia de las bebidas, la embriaguez y el alcoholismo en Honduras". Recuperado de

https://josecal.files.wordpress.com/2014/03/historia-de-lasbebidas-la-embriaguez-y-el-alcoholismo-en-hondurastegucigalpa-litografc3ada-Ic3b3pez-2013.pdf

Oliva Mancía, M. (2011). "Ciudadanía e Higienismo Social en El Salvador, 1880-1932". Recuperado de http://www. uca.edu.sv/filosofia/admin/files/1288365660.pdf

Escalante Arce, P.; López, M.; Zúñiga, L. (2008). “Los estancos, las prácticas monopólicas y las rentas del Estado en El Salvador". Superintendencia de Competencia de El Salvador.

Heller, A. (2003). "Memoria cultural, identidad y sociedad civil". Recuperado de http://afoiceeomartelo.com.br/ posfsa/Autores/Heller,\%20Agnes/Heller,\%20Agnes\%20
-\%20Memoria\%20cultural,\%20identidad\%20y\%20 sociedad\%20civil.pdf

Hernández, A. (2006). "Las fronteras de la identidad a través de la memoria. El caso de la cordillera de Nahuaterique". Tesis inédita. Universidad Tecnológica de El Salvador.

Martínez Quintero, F. (2009). "Identidad y desplazamiento forzado: el tránsito y la resignificación de sí mismo y de los otros próximos". Recuperado de http:// biblioteca.clacso.edu.ar/Colombia/alianza-cindeumz/20130321050333/TesisFelipeMartinez.pdf

Moreno, J.; Pérez, E.; Nápoles, P. (2004). "El Consenso de Washington: aciertos, yerros y omisiones". Recuperado de http://biblioteca.hegoa.ehu.es/ system/ebooks/14974/original/El_Consenso_de_ Washington._Aciertos_Yerros_y_Omisiones.pdf

Moreno, R. (2004). “La globalización neoliberal en El Salvador. Un análisis de sus impactos e implicaciones". Recuperado de http://mon-3.org/pdf/elsalvador.pdf

Ramos E. (2012). "Transnacionalización de la sociedad salvadoreña producto de las migraciones". Recuperado de http://www.utec.edu.sv/media/ investigaciones/files/11. 